\title{
PERCEPÇÕES SOBRE A COMPETÊNCIA SOCIOAFETIVA DE CORDIALIDADE E A HUMANIZAÇÃO DA TUTORIA A DISTÂNCIA
}

André Tenório | tenoriocederj@gmail.com

Doutorado em Física pelo Centro Brasileiro de Pesquisas Físicas (CBPF). Professor do Instituto Federal de Educação, Ciência e Tecnologia do Rio de Janeiro. Tutor a distância da Fundação CECIERJ /UFF.

Elizete Ventura de Souto | venturasouto@bol.com.br

Especialista em Planejamento, Implementação e Gestão da Educação a Distância, atuando no Laboratório de Novas Tecnologias da Universidade Federal Fluminense (UFF).

Thaís Tenório | tenoriocalc@gmail.com

Mestre e Doutoranda em Química pela Pontifícia Universidade Católica do Rio de Janeiro (PUC-Rio).

\section{Resumo}

As percepções de tutores a distância sobre a cordialidade e a humanização de suas práticas pedagógicas foram perquiridas. Doze tutores de uma instituição privada de Ensino Superior do Estado do Rio de Janeiro participaram da pesquisa. Para sete (58\%) deles, a cordialidade seria a principal competência socioafetiva a se exigir de um tutor a distância. Foram identificadas diversas situações nas quais seria imprescindível ser cordial, como quando um aluno manifesta desestímulo ou dificuldade de aprendizagem. Todos enfatizaram a necessidade de uma postura cortês na abertura de cada nova etapa de disciplina ou curso. Entretanto, apenas cinco (42\%) reputaram-na indispensável no acolhimento de alunos. Para oito (67\%) tutores, a identificação nominal dos cursistas e, para seis $(50 \%)$, o uso de frases motivadoras seriam formas cotidianas de exercício da cordialidade.

\section{Palavras-chave}

Competência socioafetiva. Cordialidade. Tutoria a distância. 


\section{Perceptionsonthesocio-affectivecompetence of cordiality and the humanization of on-line tutoring}

\section{Abstract}

Perceptions of on-line tutors on cordiality and humanizing pedagogical practices were perused. Twelve professionals of a private higher education institution in Brazilian federal state of Rio de Janeiro took part in the research. For seven (58\%) of them, cordiality would be the main socio-affective competence required from an on-line tutor. Many situations were identified in which being cordial would be indispensable, such as when a student expresses discouragement or learning difficulties. All tutors emphasized the need of cordial attitudes upon opening each new stage of a course or of a degree program. Nevertheless, only five $(42 \%)$ tutors considered it essential in welcoming the students. Eight $(67 \%)$ and six $(50 \%)$ tutors, respectively, considered that referring to course's participants by name and employing motivational phrases constitute good ways to quotidian engage in cordial practices.

\section{Keywords}

Socio-affective competence. Cordiality. On-line tutoring.

\section{Introdução}

O tutor possui papel multifuncional na Educação a Distância. Sua atuação exige, além do conhecimento dos conteúdos e das ferramentas tecnológicas, motivar e orientar a aprendizagem prazerosa dos alunos (BELLONI, 2009; BENTES, 2009; MACHADO e TERUYA, 2009; MORAES, 2011).

O tutor, respeitando a autonomia da aprendizagem de cada cursista, estará constantemente orientando, dirigindo e supervisionando o processo de ensino-aprendizagem [...]. É por intermédio dele, também, que se garantirá a efetivação (da aprendizagem) em todos os níveis (PRETI, 1996, p. 27).
Um desempenho eficaz do tutor no processo de ensino-aprendizagem a distância demanda uma postura embasada na relação entre os saberes científicos, tecnológicos, didático-pedagógicos e cotidianos. Isso requer o emprego de inúmeras competências, como as socioafetivas (COMPARIN, 2013; FARIAS, 2013; LAGUARDIA et al, 2010; PERRENOUD, 2004).

Borges e Souza (2012) citaram quatro grupos de competências principais que demarcariam a ação da tutoria a distância: as competências pedagógicas, socioafetivas, tecnológicas e autoavaliativas.

Para Aretio (2002), a competência socioafetiva é a habilidade de relacionamento e de interação do tutor, com o intuito de envolver e motivar o aluno no processo ensino-aprendizagem por meio da afetividade; segundo Borges e Souza (2012, p. 6), "diz respeito a habilidades ligadas ao relacionamento com o aluno, a afetividade desenvolvida durante o processo de ensino-aprendizagem e a criação de um ambiente virtual pautado no acolhimento e no respeito ao próximo".

Embora muitas vezes a dimensão afetiva seja posta em segundo plano no processo de construção do conhecimento, sua importância para o desenvolvimento cognitivo é intensamente discutida por vários autores que fundamentam o presente estudo.

Com base em uma perspectiva histórico-cultural, a teoria de Wallon destaca-se nos estudos sobre afetividade, afirmando em sua teoria da Psicogênese da Pessoa Completa que a dimensão afetiva, ao longo de todo o desenvolvimento do indivíduo, tem papel fundamental para a construção da pessoa e do conhecimento.

Segundo esse autor (Wallon), o termo afetividade corresponde às primeiras expressões de sofrimento $e$ de prazer que a criança experimenta, sendo essas manifestações de tonalidades afetivas ainda em estágio primitivo, ou seja, de base orgânica, e têm por fundamento o tônus. Este, por sua vez, representa a base de onde sucedem as reações afetivas e mantém uma relação estreita com a afetividade durante o processo de desenvolvimento humano. Ao se desenvolver, a afetividade passa a ser fortemente influenciada pela ação do meio social. Tanto que este autor defende uma evolução progressiva da afetividade, cujas manifestações vão se distanciando da base orgânica, tornando-se cada vez mais relacionadas ao social (VERAS e FERREIRA, 2010, p. 20). 
Freire (1995), Perrenoud (2004) e Ferreira e Acioly-Régnier (2010) destacaram a participação da afetividade na educação. Segundo Ferreira e Acioly-Régnier (2010), a aprendizagem seria um processo que engloba em um movimento dialético a afetividade, a cognição e os níveis biológicos e socioculturais.

\begin{abstract}
Podemos definir a afetividade como o domínio funcional que apresenta diferentes manifestações que irão se complexificando ao longo do desenvolvimento e que emergem de uma base eminentemente orgânica até alcançarem relações dinâmicas com a cognição, como pode ser visto nos sentimentos (FERREIRA; ACIOLY-RÉGNIER, 2010, p. 26).
\end{abstract}

Os debates acerca dos aspectos afetivos envolvidos no processo ensino-aprendizagem levaram à discussão a respeito da afetividade na $\mathrm{EaD}$ e, consequentemente, à reflexão sobre o desenvolvimento das competências socioafetivas para o trabalho tutorial (ARREDONDO, 1994; ARETIO, 2002; ANDRADE, 2007; BORGES; SOUZA, 2012; COMIN; OLIVEIRA, 2013; POSSA et al, 2013).

Bolívar (2002, p. 220) ressalta que os alunos querem "professores que exerçam sua autoridade com firmeza e tolerância, que os ajudem e orientem $e$ os tratem com cordialidade e afeto". O tutor na EaD é o educador responsável por orientar, mediar e motivar a aprendizagem. A sua relação com os alunos inclui várias formas de interação e trocas de experiências, o que acarreta, em geral, grande proximidade (ANDRADE, 2007; BELLONI, 2009; BENTES, 2009; FARIAS, 2013; PRETI, 1996). Possa (2013) e Comin e Oliveira (2013) inclusive destacam o tutor como "a base humana do ensino a distância".

O ensino a distância fundamentado nas competências socioafetivas tem a qualidade do processo de ensino-aprendizagem dependente de um ambiente virtual prazeroso e humanizado. Nele, o tutor planeja suas ações para criar um clima favorável em um espaço que envolve aspectos interpessoais, criatividade, diálogo e socialização.

O emprego das competências socioafetivas durante a tutoria promoveria, então, um ambiente propí- cio ao ensino e à aprendizagem e poderia até diminuir as taxas de evasão dos cursistas (ANDRADE, 2007; DORJÓ, 2011).

\begin{abstract}
Apesar de uma variedade de estudos que descrevem as qualidades de tutores em um curso de $\mathrm{EaD}$, quatro qualidades principais parecem se repetir. São elas: cordialidade, capacidade de aceitação, honradez e empatia. [...] pode-se encontrar o tutor ideal se forem somadas às quatro qualidades descritas a possibilidade de uma escuta e leitura ativa e inteligente. Por leitura e escuta ativa pode-se compreender a atitude de interesse no que é dito (ARETIO, 1994, p. 313).
\end{abstract}

Posteriormente, Aretio ressaltou que, apesar de uma gama de estudos descreverem os atributos necessários aos tutores de cursos a distância, as quatro qualidades já mencionadas pelo autor pareciam se repetir.

Nesta pesquisa, a percepção de tutores sobre a cordialidade foi analisada.

\subsection{A figura do tutor e a cordialidade}

Na configuração atual das instituições de ensino da sociedade brasileira, a atividade mais relevante não é a transferência de conteúdos aos educandos, mas o desenvolvimento de competências. Afinal, não adianta possuir um conhecimento e não possuir as habilidades para aplicá-lo quando se faz necessário.

Isso converge com a função do docente nos tempos atuais descrita pelo estudioso Perrenoud ao ressaltar que "mais do que ensinar, trata-se de fazer aprender [...] concentrando-se na criação, na gestão e na regulação das situações de aprendizagem" (PERRENOUD, 2000, p. 139). Nesse contexto, o tutor como educador deve ensinar o aluno a aprender, mais do que repassar conceitos.

$\mathrm{Na} \mathrm{EaD}$, as metodologias empregadas no processo de ensino-aprendizagem envolvem as tecnologias de informação e comunicação (TIC) como recursos didático-pedagógicos. As TIC devem ser usadas e aprimoradas pelo tutor, com o objetivo de alcançar práticas educativas compromissadas com as mudan- 
ças sociais (COMPARIN, 2013; FARIAS, 2013; PERRENOUD, 2000; PRETI, 1996).

Nesse sentido, o tutor precisa desenvolver novas competências voltadas para estimular os cursistas $e$ propor atividades interativas e problematizadas, bem como incentivar o diálogo entre os participantes de um curso. O desenvolvimento socioafetivo baseado no diálogo cordial é essencial. Para Freire (1987, p. 83), nas relações entre educador e educando "somente o diálogo, que implica um pensar crítico, é capaz, também, de gerá-lo. Sem ele, não há comunicação e sem esta não há verdadeira educação".

O tutor é um dos elementos fundamentais para o sucesso de um curso na modalidade a distância (ANDRADE, 2007; BELLONI, 2009). Seu papel principal é atuar de forma cordial, interagir com os alunos e utilizar as habilidades e competências necessárias à realização de suas atividades. Uma relação cordial entre o tutor e o aluno interfere de forma significativa no comportamento do aluno a distância (ANDRADE, 2007; ARETIO, 1994).

Uma tutoria cordial é aquela que faz os cursistas se sentirem acolhidos, respeitados e confortáveis (ARETIO, 1994; ARETIO, 2002; BORGES; SOUZA, 2012; POSSA et al, 2013).

A cordialidade de um tutor pode envolver o educando no processo de ensino-aprendizagem. A parceria tutor-aluno é uma forma de alcançar o objetivo de "aprender a aprender", de modo a estimular os cursistas a buscar seus próprios conhecimentos e desenvolver sua autonomia. Aretio (2002, p. 117) destaca que a docência na EaD deve "ser focada na motivação, promoção de uma aprendizagem independente e autônoma".

Em um ambiente virtual de aprendizagem (AVA) caracterizado como cordial, o tutor busca construir um relacionamento agradável com o grupo em que atua. Isso favorece o desenvolvimento do processo ensino-aprendizagem e contribui efetivamente para evitar a evasão dos cursistas, um dos vilões nos cursos de $\mathrm{EaD}$ (ANDRADE, 2007).

Ser cordial é agir de forma afável, tratar os alunos de modo respeitoso e sensível, demonstrar sinceridade e elogiar mais os acertos que apontar os erros.
A cordialidade deve estar presente na hora de receber os alunos no início de cada módulo do curso, ao fazê-los se sentirem bem-vindos, respeitados, confortáveis e estimulados a continuar a construção do conhecimento de forma prazerosa (SANTOS, 2013).

Exercer, na tutoria a distância, uma postura pautada na cordialidade e na prática do diálogo pode ajudar a desencadear a motivação necessária para o educando adquirir autoconfiança e uma participação ativa na construção do conhecimento (ARETIO, 2002; BORGES; SOUZA, 2012; POSSA et al, 2013).

No presente estudo, foi investigada a visão de um grupo de tutores sobre a cordialidade e seu uso no AVA.

\section{Metodologia}

No estudo foram analisadas as percepções de tutores sobre a competência socioafetiva cordialidade e sua importância nas ações cotidianas da tutoria em ambientes informatizados de ensino-aprendizagem.

A pesquisa teve caráter qualitativo. Foram investigados doze tutores que atuavam por meio de um AVA em cursos de graduação oferecidos na modalidade semipresencial. Os tutores responderam individualmente a um questionário com perguntas abertas e fechadas, aplicado pessoalmente pelos pesquisadores.

A coleta de dados ocorreu em uma universidade particular localizada no município de Nova Iguaçu (RJ) em setembro de 2013, no momento mais oportuno para cada tutor e mediante assinatura de concordância e consentimento livre e esclarecido para participação no estudo.

\section{Resultados e discussões}

3.1. Dados pessoais, acadêmicos e profissionais dos tutores

A Tabela 1 mostra os dados pessoais, acadêmicos e de experiência em tutoria dos pesquisados. 
Tabela 1: Dados pessoais, acadêmicos e de experiência dos tutores.

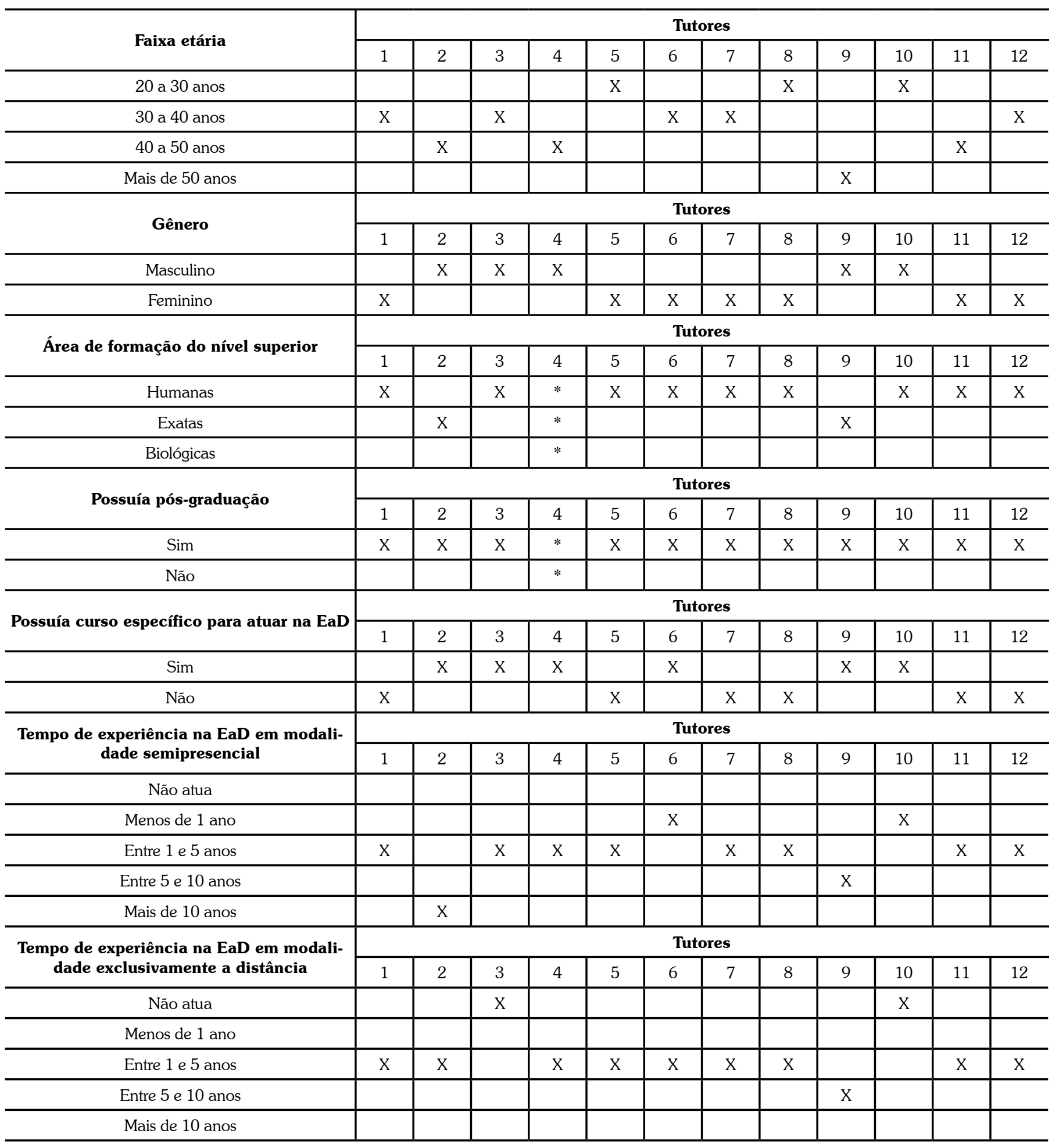

*Não respondeu.

Grande parte era do sexo feminino (58\%). A maioria tinha idade entre 20 e 40 anos (67\%), o que pode sugerir maior participação de adultos jovens como educadores do ensino a distância, pela familiaridade com as novas TIC.

Todos possuíam ensino superior ( $75 \%$ na área de Ciências Humanas e suas Tecnologias) e haviam 
realizado ao menos uma pós-graduação. Metade fez algum curso de formação em tutoria a distância. Todos trabalhavam na tutoria semipresencial, $67 \%$ de um a cinco anos. Dez (83\%) atuavam também na modalidade exclusivamente a distância.

Seis tutores $(50 \%)$ exerciam atividades exclusivamente a distância, mas não fizeram curso específico para atuar na $\mathrm{EaD}$, o que poderia prejudicar o desempenho da tutoria nessa modalidade. Além disso, supostamente eles teriam menor compreensão do valor das competências socioafetivas peculiares à $\mathrm{EaD}$ por não terem tido uma formação formal na área.

De maneira geral, a tutoria na instituição era exercida por mulheres de 20 a 40 anos, graduadas na área de Ciências Humanas e pós-graduadas, sem curso de formação para EaD e com experiência de um a cinco anos, tanto na tutoria semipresencial quanto na exclusivamente a distância.
3.2. As competências socioafetivas: ênfase na cordialidade

Borges e Souza (2012, p. 5) afirmaram que as competências socioafetivas necessárias a um tutor a distância "envolvem os aspectos interpessoais, a comunicação individual, a criatividade e a socialização contribuindo para um ambiente agradável". Dos doze pesquisados, $83 \%$ afirmaram conhecer formalmente tais competências.

Os dois que as desconheciam atuavam na modalidade a distância, um era pedagogo com especialização em Orientação Educacional e o outro possuía formação específica para a tutoria a distância.

Dos dez pesquisados cônscios das competências socioafetivas, quatro relataram ter obtido o conhecimento por meio de curso de capacitação de tutores. Outros cinco aprenderam-nas apenas durante a prática profissional e um no curso superior (em Letras).

Tabela 2: Ordem de importância das competências socioafetivas segundo cada tutor (1 representa a mais importante e 4 a menos importante)

\begin{tabular}{c|c|c|c|c}
\hline \multirow{2}{*}{ Tutores } & \multicolumn{4}{|c}{ Competências socioafetivas } \\
\cline { 2 - 5 } & Aceitação & Cordialidade & Empatia & Honradez \\
\hline Tutor 1 & 3 & 4 & 1 & 2 \\
\hline Tutor 2 & 2 & 3 & 4 & 1 \\
\hline Tutor 3 & 2 & 1 & 4 & 3 \\
\hline Tutor 4 & 2 & 1 & 1 & 3 \\
\hline Tutor 5 & 3 & 2 & 4 & 4 \\
\hline Tutor 6 & 4 & 1 & 4 & 3 \\
\hline Tutor 7 & 2 & 1 & 2 & 3 \\
\hline Tutor 8 & 2 & 1 & 3 & 3 \\
\hline Tutor 9 & 1 & 4 & 2 & 4 \\
\hline Tutor 10 & 1 & 2 & 4 & 3 \\
\hline Tutor 11 & 4 & 1 & 3 & 3 \\
\hline Tutor 12 & 2 & 1,8 & & 2,8 \\
\hline Média & 2,3 & & 4 & 4 \\
\hline
\end{tabular}

A Tabela 2 apresenta, conforme a opinião de cada tutor, a ordem de importância atribuída às competências socioafetivas.
Dentre os doze pesquisados, mais da metade $(58 \%)$ elegeu a cordialidade como a competência mais importante. A empatia e a aceitação ficaram em- 
patadas, escolhidas como a mais importante por apenas dois tutores. Já a honradez foi selecionada como a mais valiosa por somente um $(8 \%)$. A empatia foi considerada a menos importante dentre as competências por metade dos pesquisados.
As respostas organizadas na Tabela 2 revelam que, segundo as percepções dos tutores, a cordialidade seria a competência socioafetiva mais importante e a empatia, a menos importante. A aceitação e a honradez teriam valor intermediário.

Tabela 3: Significado da cordialidade na tutoria a distância segundo os tutores

\begin{tabular}{l|c}
\hline \multicolumn{1}{c|}{ Significado da cordialidade } & Total de tutores \\
\hline $\begin{array}{l}\text { Aceitar/compreender a realidade do aluno que, em seus contatos com o tutor/orientador, deve se sentir participante ativo do } \\
\text { processo de ensino }\end{array}$ & 3 \\
\hline $\begin{array}{l}\text { Agir de forma afável, tratar os alunos de modo respeitoso e sensível, demonstrar sinceridade e elogiar mais os acertos que } \\
\text { apontar os erros }\end{array}$ & 8 \\
\hline $\begin{array}{l}\text { Perceber o outro e identificar suas necessidades } \\
\text { Ser humilde na postura com o aluno, além de ser honesto consigo mesmo e com o cursista na certeza de que não existe o } \\
\text { detentor absoluto do saber }\end{array}$ & 0 \\
\hline
\end{tabular}

Conforme os resultados dispostos na Tabela 3, oito pesquisados $(67 \%)$ reconheceram o significado de cordialidade como Agir de forma afável, tratar os alunos de modo respeitoso e sensível, demonstrar sinceridade e elogiar mais os acertos que apontar os erros. Isso mostra que a maioria reconheceu o que é a cordialidade. Desses oito, seis atuavam na modalidade exclusivamente a distância.

Três tutores (25\%) responderam que o significado da palavra cordialidade era Aceitar e compreender a realidade do aluno [...], o que demonstrou confusão entre cordialidade e aceitação. Esses trabalhavam na modalidade a distância, mas não tinham curso para atuar em EaD.Um dos pesquisados (8\%) afirmou não conhecer formalmente as competências socioafetivas necessárias a um tutor a distância. Outro entrevistado $(8 \%)$ confundiu com empatia, embora tivesse formação específica para atuar na EaD. Logo, 33\% dos pesquisados não deviam praticar adequadamente os preceitos da cordialidade em suas atividades de tutoria, pois nem conheciam o seu significado.

A Tabela 4 expõe os momentos da tutoria nos quais a cordialidade seria imprescindível. Cinco tutores $(42 \%)$ julgavam que a cordialidade deveria Estar presente na hora de receber os alunos no início de cada módulo do curso [...]. Quatro (33\%) acreditavam ser indispensável no momento de orientar um aluno que necessitasse auxílio para realizar uma tarefa. Três $(25 \%)$ indicaram a necessidade de ser cordial no desenvolvimento do trabalho coletivo.

De acordo com as percepções dos pesquisados, é preciso ser cordial em diferentes momentos durante a tutoria. Mas, no início de cada etapa, a cordialidade merece maior atenção. Eles acreditam que uma postura cordial motiva o cursista e promove a interação entre tutor e cursista. Os tutores julgaram a cordialidade como desnecessária para reconhecer o desconhecimento sobre determinado assunto.

Tabela 4: Os momentos da tutoria em que a cordialidade é imprescindível segundo os tutores

\begin{tabular}{c|c} 
Quando a cordialidade é imprescindível? & Total \\
\hline $\begin{array}{c}\text { No desenvolvimento do trabalho coletivo, que deve ser pautado no diálogo, no debate, no confronto, na discussão de pontos de vista e, } \\
\text { principalmente, no respeito mútuo devido à diversidade cultural }\end{array}$ & 3 \\
\hline $\begin{array}{c}\text { Deve estar presente na hora de receber os alunos no início de cada módulo do curso ao fazê-los se sentirem bem-vindos, respeitados, con- } \\
\text { fortáveis e estimulados a continuar sua caminhada de forma prazerosa, desenvolvendo um clima de autoconfiança }\end{array}$ & 5 \\
\hline $\begin{array}{c}\text { No momento em que o aluno necessite de auxílio para a realização da tarefa, ao perceber a aflição do aluno o tutor pode orientá-lo de } \\
\text { maneira que ele consiga o entendimento necessário para a realização da mesma, agindo de maneira humana e afetiva }\end{array}$ & 4 \\
\hline Quando reconhece desconhecer determinado assunto e que pesquisará uma resposta para o aluno, sendo o mediador da aprendizagem & 0 \\
\hline
\end{tabular}


Tabela 5: Situações problemáticas passíveis de serem solucionadas com a cordialidade

\begin{tabular}{c|c}
\hline Situações problemáticas a serem solucionadas com a cordialidade & Total de tutores \\
\hline Baixa participação no AVA de toda a turma & 3 \\
\hline Baixa participação no AVA de um cursista em particular & 2 \\
\hline Agressividade entre colegas de uma disciplina & 3 \\
\hline Baixa interação com os colegas & 4 \\
\hline Desestímulo & 5 \\
\hline Dificuldade no processo ensino-aprendizagem & 5 \\
\hline Pouco contato com o tutor & 3 \\
\hline Presunção do cursista & 1 \\
\hline Questionamento à competência técnica do tutor & 0 \\
\hline
\end{tabular}

A Tabela 5 apresenta situações problemáticas passíveis de serem solucionadas com a competência socioafetiva cordialidade. Cinco pesquisados $(42 \%)$ acreditavam que tanto o desestímulo quanto a dificuldade no processo ensino-aprendizagem poderiam ser solucionados por meio de uma postura cordial do tutor. Quatro (33\%) citaram a baixa interação com os colegas. Três (25\%), a baixa participação de toda a turma no AVA, a agressividade entre colegas de uma disciplina e o pouco contato com o tutor. Apenas um (8\%) mencionou que a presunção de um cursista poderia ser amenizada por meio da cordialidade.

Os tutores foram também questionados sobre a necessidade de dar atenção especial à cordialidade nos momentos de abertura de cada nova etapa do curso. Eles foram unânimes em responder que em momentos de abertura se deve dar especial atenção à cordialidade. Dado o fato de cinco tutores (42\%) considerarem-na indispensável no acolhimento dos alunos no início de cada módulo do curso (Tabela 4), provavelmente sete tutores (58\%) a achavam uma boa competência, mas não essencial.

Ao serem questionados sobre quais seriam as formas de colocar a cordialidade em prática na abertura de uma etapa (Tabela 6), as respostas foram diversas.

Oito $(67 \%)$ indicaram referir-se aos cursistas nominalmente, porque dessa forma o tutor mostraria conhecer aquele aluno. Seis $(50 \%)$ citaram o emprego de frases motivadoras e que instem à participação como "Venha, participe do debate.". Quatro (33\%) utilizavam tratamentos como: "caros alunos", "prezados cursistas".

Tabela 6: Forma como os tutores acreditavam colocar a cordialidade em prática na abertura de uma etapa do curso ou de um fórum

\begin{tabular}{|c|c|}
\hline Como ser cordial na abertura do curso? & Total \\
\hline Com o uso da expressão "bem-vindos" no texto & 4 \\
\hline Dirigir-se-ia aos alunos nominalmente & 8 \\
\hline Com o uso de expressões coloquiais positivas & 1 \\
\hline Chamaria os alunos para a discussão com frases como: "Venha, participe do debate" & 6 \\
\hline
\end{tabular}


Quatro (33\%) mencionaram O uso da expressão "bem-vindos" no texto como uma boa forma de mostrar uma postura cordial. Segundo os tutores, embora tal competência não deva aparecer somente no início do curso, empregar essa expressão nos momentos de abertura de cada nova etapa seria uma forma de apresentar um ambiente propício à aprendizagem e à participação do aluno.

Grande parte $(33 \%)$ praticaria a cordialidade por meio de Uma mensagem de abertura escrita inteiramente em linguagem dialógica, porque promoveria um ambiente cordial favorável ao aprendizado. Apenas um tutor (8\%) empregaria Expressões coloquiais positivas.

Nenhum praticaria a cordialidade Com uma mensagem de abertura escrita inteiramente em linguagem dissertativa, por imaginar a possibilidade de tal linguagem, caracterizada pela impessoalidade, causar distanciamento entre o tutor e o aluno.

Os tutores tinham preferência por colocar a cordialidade em prática ao identificar nominalmente os alunos, por entenderem que eles sentir-se-iam bem-vindos, respeitados e estimulados a continuar sua caminhada de forma prazerosa, desenvolvendo um clima de autoconfiança.

Ao final das questões, foi solicitado aos pesquisados que narrassem uma situação problemática que tivessem conseguido contornar pelo emprego de competências socioafetivas. Apenas dois responderam, mas brevemente. As transcrições estão dispostas a seguir.

Tutor 8: "Podemos nos deparar com expressões irônicas nos AVAs, é necessário ter flexibilidade e postura ética para trabalhar tal situação".

Tutor 9: "O aluno postar mensagem na internet como se fosse dele".

O Tutor 8 não pareceu ter narrado um fato ocorrido com ele, contudo achou importante mencionar algo que poderia acontecer e colocar em destaque a necessidade de ser flexível e ter uma postura ética. Quando os cursistas assumem posturas irônicas, a competência honradez (ARETIO, 1994) deve ser pos- ta em prática.

Semelhantemente ao Tutor 8, o Tutor 9 pareceu descrever uma situação hipotética. Ele expôs uma circunstância de cópia indevida ou plágio, porém não citou nenhuma competência que poderia contornar o caso. Para resolver tal situação, o tutor poderia usar a cordialidade, porém apontando ao aluno a competência honradez, para que ele fizesse uma reflexão sobre seus atos.

De modo geral, a maioria dos pesquisados afirmou conhecer as competências socioafetivas necessárias a um tutor da $\mathrm{EaD}$ e destacou a cordialidade como a principal. Muitos reconheceram seu significado e consideraram-na imprescindivel ao receber os alunos no início do curso.

Todos julgaram ser necessário dar especial atenção à cordialidade nos momentos de abertura de cada nova etapa do curso. Como forma de exercício da cordialidade no AVA, a maioria optava por identificar os alunos nominalmente.

\section{Conclusões}

A evolução tecnológica leva à reflexão sobre as bruscas mudanças acontecidas em todos os campos, inclusive no educacional, em que cada vez mais pessoas buscam a EaD como forma viável para suprir suas necessidades de formação profissional ou continuada, em função do crescente número de cursos nessa modalidade.

Para acompanhar o ritmo dessas mudanças, os profissionais da área educacional, além da renovação de seus conhecimentos por meio de formação continuada, precisam acompanhar as inovações técnicas e tecnológicas surgidas a cada novo ano.

Contudo, para os profissionais exercerem suas funções na $\mathrm{EaD}$, não basta empregar métodos modernos e tecnologias avançadas. A concretização do processo de ensino-aprendizagem a distância necessita de outras habilidades, como as competências socioafetivas.

O tutor a distância, educador com atuação muito próxima ao aluno, deve ser capaz de estimular os 
participantes de um curso de EaD por uma comunicação cordial, prazerosa e instigante, deixando-os mais confortáveis e seguros para a interação com todo o grupo. Nesse contexto, a competência socioafetiva cordialidade pode auxiliar o tutor em suas atividades.

Na presente pesquisa, a importância da cordialidade nas práticas pedagógicas da tutoria a distância foi investigada segundo as percepções de doze tutores de uma instituição particular localizada no Estado do Rio de Janeiro.

Dez tutores (83\%) afirmaram conhecer as competências socioafetivas necessárias a um tutor de $\mathrm{EaD}$; desses, quatro relataram ter obtido o conhecimento por meio de um curso de capacitação de tutores. Os dois que admitiram desconhecer as competências atuavam na modalidade exclusivamente a distância. Grande parte dos pesquisados $(58 \%)$ elegeu a cordialidade como a competência socioafetiva mais importante.

Apesar de a maioria afirmar conhecer as competências socioafetivas e mais da metade ter escolhido a cordialidade como a mais importante, $33 \%$ confundiram seu significado.

Cinco pesquisados (42\%) achavam que tanto o desestímulo quanto a dificuldade no processo de ensino-aprendizagem poderiam ser solucionados por meio de uma postura cordial do tutor.
Grande parte dos tutores (42\%) julgava a cordialidade imprescindível no acolhimento dos alunos no início de cada módulo do curso. Porém, todos acreditavam ser necessário dar especial atenção a essa competência em momentos de abertura. $\mathrm{Na}$ abertura de uma etapa do curso ou de um fórum, a preferência era colocar a cordialidade em prática ao identificar nominalmente os cursistas. Os tutores entendiam que isso fazia com que eles se sentissem estimulados a interagir, a buscar o conhecimento e a cumprir suas tarefas do curso.

De acordo com os pesquisados, é preciso conhecer a cordialidade para aplicá-la nas ações da tutoria a distância, em especial na comunicação com os alunos em um AVA, para se promover a interação de forma motivadora.

O intuito desta pesquisa foi mostrar o caminho seguido por um grupo de tutores ao empregar a cordialidade para apontar em que momentos tal competência era utilizada no AVA e de que maneira.

Trabalhos futuros podem investigar as percepções de alunos a distância de como a postura cordial de um tutor influenciaria o processo de ensino-aprendizagem. Espera-se que o presente estudo ajude a mostrar a importância da cordialidade e de uma postura humanizada na tutoria a distância.

\section{Referências}

ANDRADE, J. B. F. A mediação na tutoria on-line: o entrelace que confere significado à aprendizagem. 2007. 94 f. Dissertação (mestrado em Tecnologia da Informação e Comunicação na formação em Educação a Distância). Universidade Federal do Ceará e Universidade Norte do Paraná, Salvador, 2007.

ARETIO, L. G. Educación a distancia hoy. Madrid: UNED, 1994.

La educación a distancia: de la teoría a la práctica. Barcelona: Ariel, 2002.

ARREDONDO, S. C. La acción tutorial en la enseñanza a distancia. 1994. 55 f. Trabalho de conclusão de curso (especialização em Educação de Adultos). Instituto Universitário de Educação a Distância, Madri, 1994.

BELLONI, M. L. Educação a distância. 5 ed. Campinas: Autores Associados, 2009.

BENTES, R. F. A avaliação do tutor. In: LITTO, F. M.; FORMIGA, M. (Orgs.). Educação a distância: o estado da arte. São Paulo: Pearson, 2009, p. 166-170. 
BOLÍVAR, A. Profissão de professor: o itinerário profissional e a construção da escola. São Paulo: EDUSC, 2002. BORGES, F. V. A.; SOUZA, E. R. Competências essenciais ao trabalho tutorial: estudo bibliográfico. Simpósio Internacional de Educação a Distância, 1., 2012, São Carlos. Anais eletrônicos... São Carlos: Universidade Federal de São Carlos, 2012. Disponível em: <http://sistemas3.sead.ufscar.br/ojs1/index.php/sied/article/ view/178/85 > . Acesso em: 12 fev. 2014.

COMPARIN, E. R. A. Concepções e tendências do trabalho docente na educação a distância: um estudo de caso. 2013. 220 f. Tese (doutorado em Educação). Universidade Federal do Paraná, Curitiba, 2013.

DORJÓ, D. S. Relações Afetivas: reais possibilidades na educação a distância. Texto livre: linguagem e tecnologia, Belo Horizonte, v. 4, n. 2, p. 1-10, 2011. Disponível em: < http://www.periodicos.letras.ufmg.br/ index.php/textolivre/article/view/104>. Acesso em 12 fev. 2014.

FARIAS, S. C. Os benefícios das tecnologias da informação e comunicação (TIC) no processo de educação a distância (EaD). Revista Digital de Biblioteconomia e Ciência da Informação, Campinas, v. 11, n. 3, p. 15-29, set./dez. 2013.

FERREIRA, A. L.; ACIOLY-RÉGNIER, N. M. Contribuições de Henri Wallon à relação cognição e afetividade na educação. Curitiba: Editora UFPR, 2010.

FREIRE, P. Pedagogia do oprimido. São Paulo: Paz e Terra, 1987.

A Educação na cidade. 2 ed. São Paulo: Cortez, 1995.

GASPAR, F. D. R.; COSTA, T. A. Afetividade e atuação do psicólogo escolar. Revista Semestral da Associação Brasileira de Psicologia Escolar e Educacional, São Paulo, v. 15, n. 1, p.121-129, jan./jun. 2011.

LAGUARDIA, J.; MACHADO, R.; COUTINHO, E. Interação e comunicação em ambientes virtuais de aprendizado. Revista de Ciência da Informação, Brasília, v. 11, n. 4, ago. 2010. Disponível em: <http:// www.dgz.org.br/ago10/Art_03.htm>. Acesso em: 12 fev. 2014.

MACHADO, S. F; TERUYA, T. K. Mediação pedagógica em ambientes virtuais de aprendizagem: a perspectiva dos alunos. Congresso Nacional de Educação, 9, 2009, Pará. Anais eletrônicos... Pará: EDUCERE, 2009. Disponível em: <http://www.portugues.seed.pr.gov.br/arquivos/File/ead/suelen.pdf>. Acesso em 12 fev. 2014.

MORAES, E. E. M. Repensando o papel do professor e suas práticas pedagógicas em EaD. 2011. 18 f. Trabalho de conclusão de curso (Curso de Gestão de Polos) Universidade Federal de Pelotas, Rio Grande do Sul, 2011. Disponível em: <http://pt.scribd.com/doc/57203785/REPENSANDO-O-PAPEL-DO-PROFESSORTUTOR-E-SUAS-PRATICAS-PEDAGOGICAS-EM-EAD>. Acesso em 12 fev. 2014.

MOREIRA, P. A. S.; PINHEIRO, A.; GOMES, P.; COTTER, M. J.; FERREIRA, R. Development and evaluation of psychometric properties of an inventory of teachers' perceptions on socio-emotional needs. Psicologia: Reflexão e Crítica, Porto Alegre, v. 26, n. 1, p. 67-76, 2013.

OSTI, A.; BRENELLI, R. P. Sentimentos de quem fracassa na escola: análise das representações de alunos com dificuldades de aprendizagem. Psico-USF, Bragança Paulista, v. 18, n. 3, p. 417-426, set./dez. 2013.

PERRENOUD, P. Novas competências para ensinar. Porto Alegre: Artmed, 2000.

Dez novas competências para ensinar. Porto Alegre: Artmed, 2004. 
POSSA, A. D.; COMIN, L. G. M.; OLIVEIRA, F. M. G. O tutor e os aspectos afetivos da aprendizagem em educação a distância. In: Seminário de Educação a Distância, 1, 2013, Santa Catarina. Anais eletrônicos... Santa Catarina: IFSC, 2013. Disponível em: <http://seminarioead.ifsc.edu.br/files/2013/03/Artigo_Andr\%C3\%A9_ Dala_Possa.pdf >. Acesso em: 12 fev. 2014.

PRETI, O. Educação a distância: inícios e indícios de um percurso. Cuiabá: UFMT, 1996.

SANTOS, M.P. Tutoria em EaD: um elo de interação entre ensinantes e aprendentes virtuais. Revista científica de educação a distância Paidéi@, Santos, v. 4, n. 7, 2013. Disponível em: < http://revistapaideia. unimesvirtual.com.br/index.php?journal = paideia\&page $=$ article\&op =viewFile\&path[] =259\&path[] =269> . Acesso em: 12 fev. 2014.

VERAS, R.S.; FERREIRA, S.P.A. A afetividade na relação professor-aluno e suas implicações na aprendizagem, em contexto universitário. Educar em Revista, Curitiba, n. 38, p. 219-235, set./dez. 2010. 